\title{
Response to treatment with chelating agents of anaemia, chronic encephalopathy, and myelopathy due to lead poisoning
}

\author{
J. A. SIMPSON, D. A. SEATON, ${ }^{1}$ AND J. F. ADAMS \\ From the Northern General Hospital, Edinburgh, and the Western Infirmary, Glasgow
}

Chronic lead poisoning is a well-known clinical entity which is now becoming uncommon as a result of improvements in industrial hygiene applied to workers with lead. The patient with chronic lead poisoning presents commonly with abdominal pain and constipation, less commonly with a neuropathy, and rarely with a refractory anaemia. Encephalopathy due to lead poisoning is common in childhood but rare in adult life. The diagnosis is usually confirmed by the finding of an excess of lead in the blood and urine.

The present case showed rather unusual features of chronic lead poisoning; special techniques were involved in the investigation of the neurological and haematological abnormalities and the results provide information of fundamental interest on the effects of lead on these systems.

\section{METHODS}

The routine investigations were carried out by the accepted standard laboratory methods.

The radioactive chromium $\left({ }^{51} \mathrm{Cr}\right)$ technique for estimating haemolysis was based on the method of Mollison and Veall (1955) and carried out as described by Goldberg and Seaton (1960). Red cell volume was calculated from the radioactivity in a sample of venous blood obtained 20 minutes after the injection of the ${ }^{51} \mathrm{Cr}$-labelled cells, by the dilution principle.

Radioiron $\left({ }^{59} \mathrm{Fe}\right)$ uptakes and utilization tests were carried out as described by Ledlie and Baxter (1954) and Wetherley-Mein, Hutt, Langmead, and Hill (1956).

Serum $\mathrm{B}_{12}$ assay was carried out by the Euglena gracilis method of Hutner, Bach, and Ross (1956).

Electroencephalography was carried out by routine techniques. Co-axial needle electrodes with conventional amplification and cathode-ray oscilloscope recording were used for electromyography, and motor nerve conduction velocity was determined by the method of Simpson (1956). Neuromuscular transmission was investigated according to the method of Harvey and Masland (1941).

${ }^{1}$ Royal Infirmary, Edinburgh

"Southern General Hospital, Glasgow
CASE REPORT

The patient was a 39-year-old man employed as an acetylene burner for over 20 years and treated in 1949 fo: abdominal pain and constipation caused by lead poisoning. In 1955 he began to have giddy turns and occasionath 'blackouts' if working in confined spaces and by October? 1957 these attacks were more frequent. His blood pressure then was $110 / 70 \mathrm{~mm} . \mathrm{Hg}$ and he had moderate anaemia ( $\mathrm{Hb} 76 \%$ ) with reticulocytosis $(6.5 \%)$. About this datey he noticed weakness and wasting of his right hand? Radiographs of the cervical spine did not reveal a cause tof the weakness. In January 1960 he was admitted to $\$$ Western Infirmary of Glasgow as the severity of his we $\mathrm{k}$ 옹 ness was such that he was unable to feed himself. Fife complained also of poor general health, loss of appeifte and weight, and frequent attacks of light-headedness and dizziness. He stated that while at work burning leadghe rarely washed.

EXAMINATION On examination he was found to be? sallow complexion, thin, lethargic, and with a ratheo sleepy, expressionless face. The mucous membranes and palmar creases were pale, there was no lymphadenopath $\square$ or finger clubbing, and the patient was edentulous and hac no 'lead-line' on the gums. There was no hepatomegaly of splenomegaly. The blood pressure was $130 / 80 \mathrm{~mm}$. Hgi Psychological assessment showed general impairmen without specific psychological defects. Performance of memorizing and abstract reasoning tests was very poore Language function was not grossly abnormal. Vision of

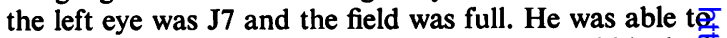
distinguish only figures with his right eye but said he had been 'blind' in this eye since childhood. Pupil reactions: were brisk though relaxation was a little slow, and there was a right internal concomitant strabismus, the crani nerves being otherwise normal. Occasional twitching of muscles was present in all limbs. The upper limbs showed gross weakness and wasting of the intrinsic muscles of both hands, especially on the right (Fig. 1), and there was less severe weakness of the more proximal muscles? including the shoulder girdle and the neck. The least affected muscles of the upper limbs were the long flexores of the fingers. Power was symmetrically but not gross reduced in the lower limbs. The upper limb reflexes werd symmetrical and very brisk, the knee and ankle jerks 


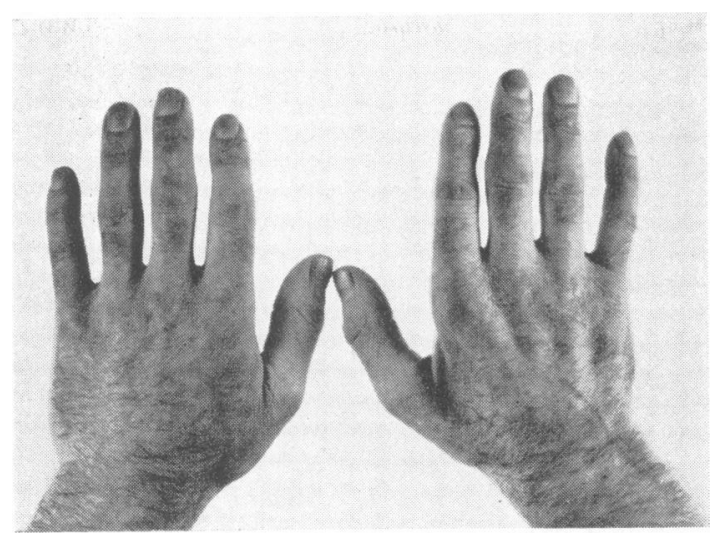

FIG. 1. Wasting of intrinsic muscles of hands, especially on the right (January 1960)

were brisk and the plantar responses flexor. Abdominal responses were depressed except in the left upper quadrant. His gait was unsteady but coordination otherwise satisfactory. Sensation was intact in all modalities.

INVESTIGATIONS The Wassermann reaction was negative in blood and cerebrospinal fluid. Haemoglobin was $\mathbf{8 . 8}$ g. $\%$; P.C.V., $30.5 \%$; M.C.H.C., $28.75 \%$; reticulocytes, $7.5 \%$; W.B.C., 5,500/c.mm.; platelets, 140,000/c.mm.; direct Coombs test negative, serum $B_{12} 760 \mu \mu \mathrm{g} . / \mathrm{ml}$., serum iron, $137 \mu \mathrm{g} . \%$; total iron-binding capacity, 260 $\mu$ g. $\%$. Ham's test was negative. Haptoglobin showed a primary acceptance pattern. Red cell fragility was normal. Sternal marrow showed normoblastic erythroid hyperplasia and stainable iron was present in the marrow aspirate.

Serum bilirubin level was $0.9 \mathrm{mg} . \%$. Urinary urobilinogen levels were 6.8 and $7.7 \mathrm{mg}$. and coproporphyrin (I and III), $280 \mu \mathrm{g}$. per 24 hours; faecal urobilinogen, 265 and $687 \mathrm{mg}$. per 24 hours. Blood lead levels were 27 and $28 \mu \mathrm{g} . \%$ and urine lead $87 \mu \mathrm{g}$. per 24 hours. Urinary excretion of creatinine was $1,166 \mathrm{mg}$. and creatine $742 \mathrm{mg}$. in 24 hours. Serum albumin was 3.8 g. $\%$, serum globulin 1.2 g. $\%$, serum cholesterol 183 mg. $\%$. The B.M.R. was $-17 \%$. Serum electrolytes were normal. Liver function tests were normal. S.G.O.T. was 42 Sigma-Frankel units. A glucose tolerance test was normal but gave a low renal threshold for glucose.

Red cell volume was $944 \mathrm{ml}$. Radioiron uptakes gave a normal pattern: radioiron utilization, $40.9 \%$ of injected dose (normal $68-86 \%$ ); radiochromium half-life, 26 days (normal 25-30).

The cerebrospinal fluid was under normal pressure and contained $25 \mathrm{mg} . / 100 \mathrm{ml}$. protein, no cells, and negative colloidal gold curve. The fluid did not fluoresce with ultra-violet light.

An electrocardiograph showed non-specific $T$ wave changes. Muscle biopsy showed no abnormality.

A radiograph of the chest was normal and skeletal survey revealed no radiological changes associated with lead poisoning.

Neurological investigations were carried out at the Northern General Hospital, Edinburgh.
E.E.G. An electroencephalograph, recorded on 21 January 1960 without previous medication and when the patient was not drowsy, showed symmetrical $7 \frac{1}{2}-8 \mathrm{c} / \mathrm{s}$ alpha rhythm in the post-central areas of each hemisphere. It desynchronized normally on visual attention. There were occasional bursts of $7 \mathrm{c} / \mathrm{s}$ theta activity in both anterior temporal leads. Hyperventilation for two minutes caused the appearance of diffuse irregular low voltage $4 \mathrm{c} / \mathrm{s}$ waves. These rapidly subsided when overbreathing was stopped.

The alpha rhythm was below the normal frequency range and the slower activities were excessive. There was no evidence of focal or paroxysmal disorders (Figs. 2a and $2 \mathrm{~b}$ ).

ELECTROMYOGRAPHY A co-axial needle electrode was inserted into the first dorsal interosseous muscle of both hands and into the right extensor digitorum longus. (Muscle localization was confirmed at end of observation by stimulating through the recording needle.) In each muscle there was marked insertion activity and slight spontaneous fibrillation but no fasciculation potentials were recorded. Some positive 'injury' potentials were recorded after movement of the needle. On voluntary contraction (Fig. 3) the majority of motor units examined were of normal dimensions and configuration but a few low-voltage, long-duration polyphasic units were recorded from the extensor digitorum longus. The number of units recruited by maximum voluntary effort was greatly reduced in each muscle. In the first dorsal interosseus muscle of the right hand the recruitment pattern was reduced to single motor units within the recording range of the electrode.

Surface (belly-tendon) electrodes on the first dorsal interosseus muscle of the right hand were used to record the response of that muscle to supramaximal electrical stimulation of the right ulnar nerve at the wrist and elbow. The latency of the response from the wrist $(9 \mathrm{~cm}$.) was $4.5 \mathrm{msec}$. and from the elbow $(35 \mathrm{~cm}$.) it was $8.5 \mathrm{msec}$., giving a calculated conduction velocity of 60 m.p.s. in the forearm. All of these figures are within the normal range (Figs. $4 \mathrm{a}$ and $4 \mathrm{~b}$ ). When the nerve was stimulated 50 times per second with a supramaximal current the evoked action potential of the muscle did not decrement.

It was concluded that there was evidence of denervation without significant collateral re-innervation (giant polyphasic units) and with normal nerve conductivity and neuromuscular transmission. The evidence pointed to a central lesion (myelopathy) rather than to a peripheral neuropathy.

PROGRESS In January 1960 the patient's urinary output of lead was $378 \mu \mathrm{g}$. in 24 hours. He was then given Penicillamine, $300 \mathrm{mg}$. six-hourly by mouth, for the next two days. On these days and on the following one he excreted $2,100,2,438$, and $1,457 \mu \mathrm{g}$. As there was a clear indication of a depot of lead in the body which could be removed it was decided to try a cheaper form of chelation treatment. Treatment with Versene, $4 \mathrm{~g}$. orally each day, was begun on 11 February 1960 and continued for nine days. The effect on the urinary lead excretion and urinary coproporphyrin excretion is seen in Table $I$. Three further similar courses of three to four days' duration were given 


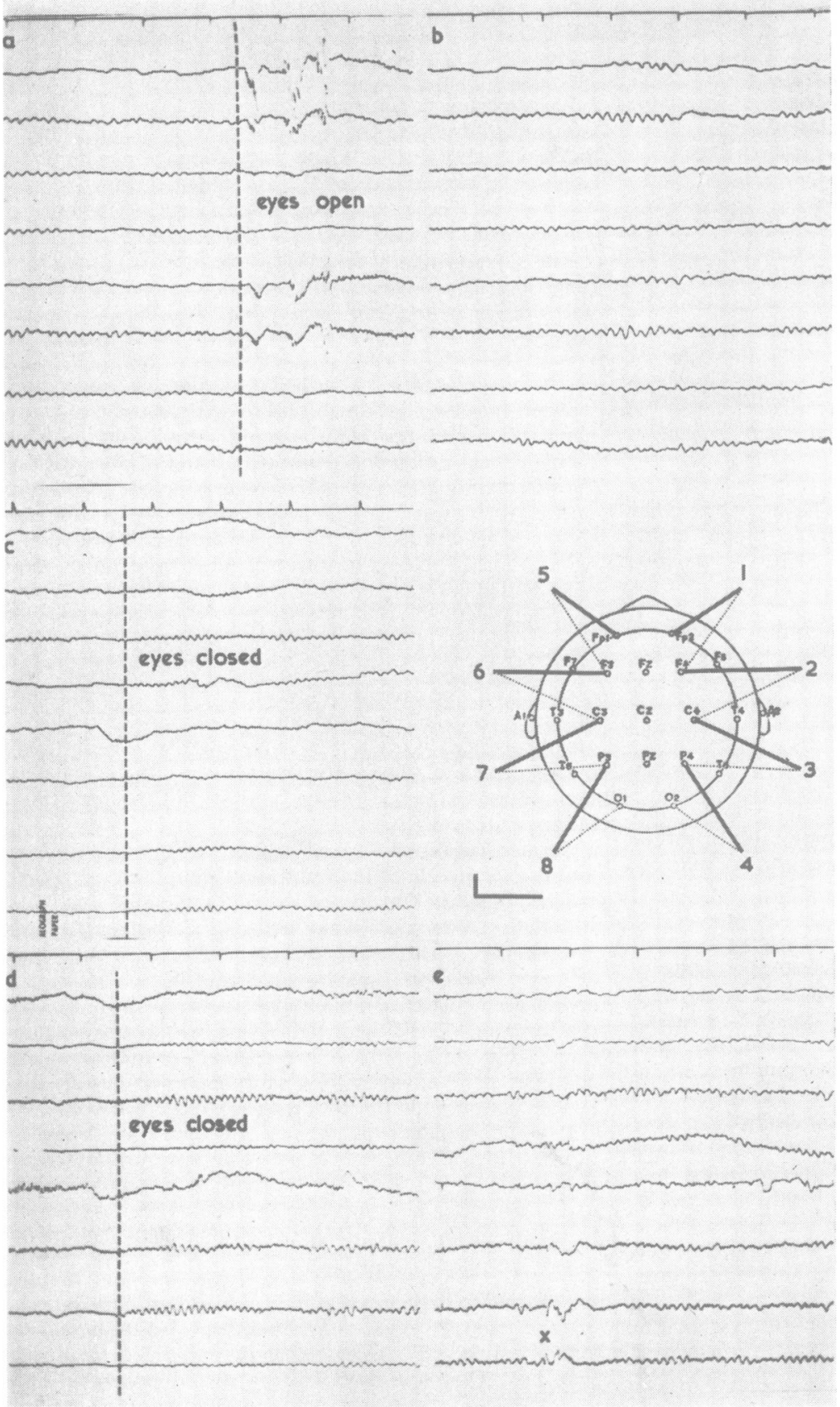

FIG. 2. Electroencephalograph $\stackrel{\text { ․․ }}{\text {. }}$ Calibration $50 \mu \mathrm{V}$ and 1 second. a. 21 January 1960 Symmetrical

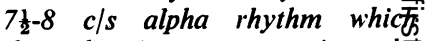
desynchronizes on opening the eyes.

b. 21 January 1960 Bilater anterior temporal $7 \mathrm{c} / \mathrm{s}$ the activity.

c. 3 June 1960 Symmetric \&્dी $8 \frac{1}{2}-9 \mathrm{c} / \mathrm{s}$ alpha rhythm appears $\overrightarrow{\mathrm{B}}$ closing the eyes.

d. 4 April 1963 Alpha rhyth $\overrightarrow{\text { mit }}$ $9-10 \mathrm{c} / \mathrm{s}$, responsive to vist attention.

e. 4 April 1963 Sharp and sloino wave discharge, focal in leff parietal region (maiked with 10

官 


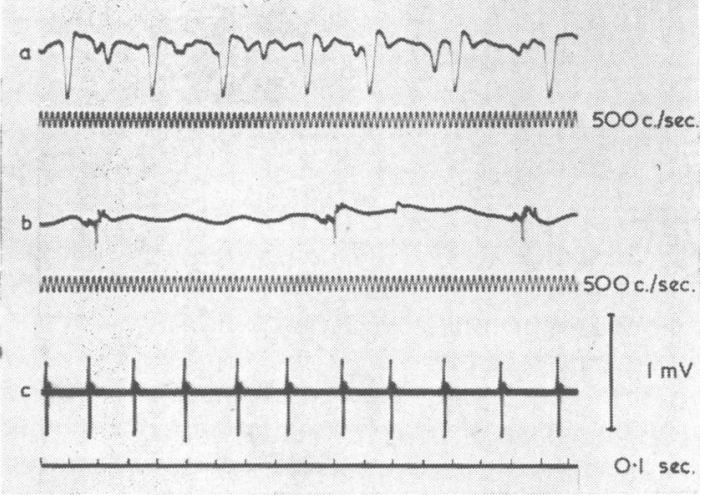

FIG. 3. Electromyographs during maximum voluntary contraction.

a. 18 January 1960 First dorsal interosseous muscle, right hand.

b. 18 January 1961 Extensor digitorum longus, right forearm.

c. 18 April 1961 First dorsal interosseous muscle, right hand.

at intervals during the next four weeks as the cheaper form of chelation therapy appeared to produce a satisfactory plumburia, though in these later courses the urinary 24-hr. excretion of lead rose to a maximum of $130 \mu \mathrm{g}$. only. During this time the haemoglobin rose steadily from an initial $8.8 \mathrm{~g} . \%$ to $13.5 \mathrm{~g} . \%$ and the reticulocytes fell from $7.5 \%$ to less than $2 \%$. The mean corpuscular haemoglobin concentration also rose from $28.75 \%$ to $31 \cdot 5 \%$

In October 1960 his haematological state was reviewed: Haemoblobin, $15 \cdot 1$ g. \%; M.C.H.C., $30.5 \%$; reticulocytes $2 \%$; serum iron, $67 \mu \mathrm{g} . \%$; total iron-binding capacity, $315 \mu \mathrm{g} . \%$; urinary urobilinogen, $6.0 \mathrm{mg} . / 24 \mathrm{hr}$.; faecal urobilinogen, $29 \mathrm{mg} . / 24 \mathrm{hr}$; blood lead, $18 \mu \mathrm{g} . \%$; urine lead, $106 \mu \mathrm{g} . \%$; radiochromium half-life, 27 days; radioiron uptakes, normal; radioiron utilization, $84.6 \%$; red cell volume, $1,623 \mathrm{ml}$.

There was a striking improvement in muscle power by June 1960 though wasting was present as before. The alpha rhythm of the E.E.G. had increased to $8 \frac{1}{2}-9 \mathrm{c} / \mathrm{s}$ (Fig. 2c). Nerve conduction was still normal. In April 1961 muscle power had become normal with the exception of persisting weakness of the right adductor pollicis and triceps brachialis and the first dorsal interosseous muscles of

TABLE

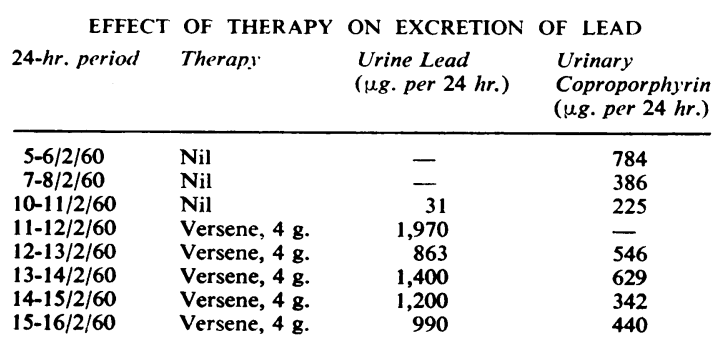

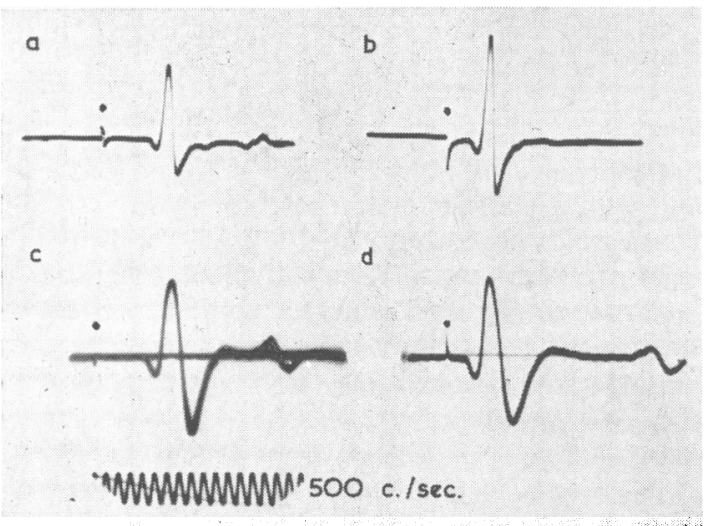

FIG. 4. Conauction velocity of right ulnar nerve. Muscle action potentials recorded by surface electrodes on first dorsal interosseous muscle. Stimulus artefacts marked by dots.

a. 18 January 1960 Stimulation at elbow.

b. 18 January 1960 Stimulation at wrist.

c. 18 April 1961 Stimulation at elbow.

d. 18 April 1961 Stimulation at wrist.

both hands, though even these were much less wasted. All tendon reflexes were still very brisk but the plantar reflexes remained flexor and twitching was no longer present. Electromyography of the first dorsal interosseous muscles showed only discrete units under voluntary control. These were normal in size and contour. There was no spontaneous activity. The conduction velocities of the forearm segment of the right and left ulnar ner ves were 49 m.p.s. in April 1961 (the lower figure for one nerve reported previously by Simpson (1962c) was due to miscalculation) (Figs. 4c and 4d). In April 1963 the conduction velocity of the same part of the right ulnar nerve was 60-65 m.p.s. and on the left it was still 49 m.p.s. The wrist and hand latencies remained below $5 \mathrm{msec}$. The E.E.G. on 4 April 1963 was recorded during a period of spontaneous drowsiness. Nevertheless the alpha rhythm had become yet a little faster $(9-10 \mathrm{c} / \mathrm{s})$ though it showed occasional episodes of $8 \mathrm{c} / \mathrm{s}$ activity bilaterally. It remained fully responsive to visual attention and the record was now well within normal limits (Fig. 2d). One burst of sharp and slow waves appeared during rebreathing, mainly on the left side (Fig. 2e). It was similar to disturbances seen in epileptic patients but its significance is uncertain as there was no recurrence. No deterioration such as would be expected in classical motor neurone disease occurred during the period April 1961 to April 1963 and, in fact, some clinical improvement continued though there was no further electromyographic improvement.

\section{DISCUSSION}

In most cases of lead poisoning the diagnosis can be suspected strongly on clinical grounds and confirmed easily by relatively simple laboratory procedures. In the present case there were good grounds for clinical suspicion: the previous history of lead 
poisoning, the known occupational risk, and an anaemia in association with neurological features. These features, however, did not provide evidence adequate to sustain a diagnosis of lead neuropathy in the presence of normal blood and urine lead levels and with a clinical picture resembling amyotrophic lateral sclerosis. In view of the social and medicolegal problems and the very different prognoses in lead neuropathy and in amyotrophic lateral sclerosis, it was felt necessary to extend the investigations until the available evidence made one or other diagnosis acceptable.

Investigation of the anaemia revealed a normal red cell survival time which showed that the accompanying reticulocytosis was not primarily the result of increased haemolysis; it may be surmised that the elevated reticulocyte count was due to the effect of lead on the immature red cells in the marrow. The occurrence of an apparent iron-deficiency anaemia in the presence of erythroid hyperplasia, normal serum iron levels, and ample stainable iron in the marrow is also compatible with an interference in haemoglobin formation. Further evidence for a dyshaemopoietic anaemia was afforded by the radioiron studies which demonstrated that, while iron passed normally to the marrow, much less than normal was being utilized. No cause, however, was found to account for the increased urobilinogenuria.

Alteration of haem synthesis by lead has previously been reported and it has been suggested that the defect is due to interference with the incorporation of iron into the protoporphyrin nucleus (McFadzean and Davis, 1949; Jandl, Inman, Simmons, and Allen, 1959). On the other hand, Eriksen (1955) found that lead exercised a strong inhibitory effect on the formation of haem due to a diminished formation of the porphyrin part of haem. It seems most likely, however, that haem synthesis is affected at several different levels (Goldberg, Smith, and Lockhead, 1963), particularly before the formation of d-aminolaevulinic acid and at the stage of incorporation of iron into protoporphyrin as shown by Goldberg, Ashenbrucker, Cartwright, and Wintrobe (1956). In a study of children with lead poisoning, Leikin and Eng (1963), found a haemolytic anaemia in some but a dyshaemopoietic anaemia in others. They concluded that the haematological defect was related to the duration of toxicity, the haemolytic anaemia occurring in the more acute cases and the dyshaemopoietic anaemia in those of longer standing. The findings in the case reported here are compatible with this hypothesis.

The therapeutic trial of Penicillamine and Versene caused an outpouring of lead in the urine but this could not be regarded as of diagnostic value in that such a result could be anticipated in a lead worker.
The more relevant aspect of Versene therapy w⿳亠口冋亍5 the restoration of haemopoiesis to normal as seen by the rise in peripheral blood values and the later normal utilization of radioiron.

Acute encephalopathy due to lead is more common in childhood than in the adult. It is manifested by coma with tremor, convulsions, and signs of cerebral oedema, and is generally considered to be due hypertension with exudative vasculitis. It may followed by mental retardation, optic atrophy, and ocular palsies but lead 'neuritis' is rare. In the aduft, on the other hand, acute lead encephalopathy rare but chronic encephalopathy causes dement characterized by lethargy and defective memory. In these patients hypertension is rare and vasculor damage cannot account for the neurological defigit though atherosclerosis is common (Aub, Fairhat, Minot, and Reznikoff, 1925). The patient reported above gave a previous history of 'blackouts' but the time he came under our observation he presented the picture of chronic lead encephalopathy. At that time he was normotensive and the only evidence $\overline{\text { gf }}$ renal damage was a lowered threshold for sugakl This may support the suggestion of Aub et al. (1929) that chronic lead encephalopathy is due to seleftive degeneration of ganglion cells. The only electroencephalographic abnormality was moderate sfowing of the alpha rhythm. When lead was eliminated. from the body by treatment the E.E.G. alpha rhy fh returned to normal but there was slight suspicion 8 est persistent convulsive tendency. There was litt any improvement in the mental state.

The neurological picture was one of bilater lower motor neurone disease of the upper limb? more marked distally and accompanied by occasiona twitching resembling fasciculation of muscles. The hyperreflexia was considered to be more in keeping with a myelopathy than a peripheral neuropatho. The absence of pathological plantar reflexes was noft considered inconsistent since the syndrome just: described is common in the earlier stages of amyotrophic lateral sclerosis. The electromyographic findings showed that there was a severe fall-out of peripheral motor neurones and few of the remaining motor units showed the electrical signs of re-innervation which commonly occurs with peripheral neuropathy. The conduction velocity of the surviving mot fibres in each ulnar nerve remained normal over. period of three years and tetanization of the nerpe did not suggest any failure to maintain production of acetylcholine (Simpson, 1962a). On these grounds well as on the clinical picture it was considered that the muscular wasting was due to disease of the anterior horn cells, and possibly also of the pyramide. tracts. The syndrome was indistinguishable from amyotrophic lateral sclerosis in every respe 
excepting its natural history. The striking recovery makes untenable a diagnosis of that disease.

Long-term follow up, now four years, suggests that the diagnosis of chronic lead myelopathy was correct.

Several types of paralysis of the limbs have been described in chronic lead poisoning, including a distal upper limb type causing wrist drop, a proximal upper limb type paralysing the biceps, deltoid, and other proximal muscles, and a type involving the small muscles of the hand predominantly. The first of these is the most common. The distribution suggests a radial neuropathy but the brachio-radialis muscle is usually spared. The third type may be associated with muscular fasciculation and hyperreflexia and is usually agreed to resemble progressive muscular atrophy. In a few cases with pathological plantar reflexes the resemblance to amyotrophic lateral sclerosis is complete. The literature on this type, reviewed by Aub et al. (1925), is unfortunately largely clinical. The few pathological reports are incomplete and date from the period before modern staining techniques. Nevertheless, Aub et al. (1925) state that anterior horn cell degeneration is most constant and that it is characterized by vacuolation of the ganglion cells, perinuclear chromatolysis, fatty pigmentation, and marked shrinkage of the cells.

Hyslop and Kraus (1923) reviewed the subject and concluded that no clear distinction could be made between a polioclastic and a peripheral type of lead 'neuritis' but that all parts of the lower motor neurone may be affected. An alternative concept of lead neuritis attributes it to segmental demyelination of peripheral motor neurones with only secondary axonal degeneration (Gombault, 1880). This is the concept which gains most acceptance at present (Greenfield, 1958). The normal conduction velocity of the nerves to the wasted muscles in the present case is more compatible with toxic neuronopathy than with primary demyelination (Simpson, 1962b, 1964). We are unable to find any reports of conduction velocity determinations on the more common type of lead neuritis with which to compare these findings. The present case has been referred to by Simpson (1962c). For these reasons we feel that the clinical and electro-physiological evidence in the present case point very strongly to degeneration of anterior horn cells. More rarely the long sensory and spino-cerebellar tracts of the spinal cord may be affected by demyelination, but there seems little doubt that, as with chronic encephalopathy, the more usual myelopathy is due to toxic changes in ganglion cells.

It has previously been considered inadvisable to de-lead a patient by mobilizing bone calcium in view of the danger of exacerbation of toxic symptoms.
We considered that this objection would not hold if lead were removed by chelating agents since the lead would be held in non-toxic form until excreted in the urine. The small risk seemed worth taking to establish the diagnosis of chronic lead encephalopathy with toxic myelopathy. The clinical improvement vindicated this policy. We believe that this case is the first in which lead myelopathy has been reversed by treatment.

We wish to thank Dr. J. A. W. McCluskie for permission to study this patient, and for helpful advice; also Professor E. J. Wayne for facilities in his Department, and Dr. A. Goldberg for urinary coproporphyrin estimations.

\section{REFERENCES}

Aub, J. C., Fairhall, L. T., Minot, A. S., and Reznikoff, P. (1925). Lead poisoning. Medicine (Baltimore), 4, 1-250.

Eriksen, L. (1955). Lead intoxication: 1. The effect of lead on the in vitro biosynthesis of heme and free erythrocyte porphyrins. Scand. J. clin. Lab. Invest., 7, 80-85.

Goldberg, A., Ashenbrucker, H., Cartwright, G. E., and Wintrobe, M. M. (1956). Studies on the biosynthesis of heme in vitro by avian erythrocytes. Blood, 11, 821-833.

- - , and Seaton, D. A. (1960). The diagnosis and management of myelofibrosis, myelosclerosis and chronic myeloid leukaemia. Clin. Radiol., 11, 266-270.

_-, Smith, J. A., and Lochhead, A. C. (1963). Treatment of leadpoisoning with oral penicillamine. Brit. med. J., 1, 1270-1275.

Gombault, A. (1880). Contribution à l'étude anatomique de la névrite parenchymateuse subaiguë et chronique; névrite segmentaire péri-axile. Arch. Neurol. (Paris), 1, 11-38.

Greenfield, J. G. (1958). Neuropathology, ch. 12, pp. 583-615. Arnold, London.

Harvey, A. M., and Masland, R. L. (1941). A method for the study of neuromuscular transmission in human subjects. Bull. Johns Hopk. Hosp., 68, 81-93.

Hutner, S. H., Bach, M. K., and Ross, G. I. M. (1956). A sugarcontaining basal medium for vitamin $B^{12}$-assay with euglena; application to body fluids. J. Protozool., 3, 101-112.

Hyslop, G. H., and Kraus, W. M. (1923). The pathology of motor paralysis by lead. Arch. Neurol. Psychiat. (Chic.), 10, 444-455.

JandI, J. H., Inman, J. K., Simmons, R. L., and Allen, D. W. (1959). Transfer of iron from serum iron-binding protein to human reticulocytes. J. clin. Invest., 38, 161-185.

Ledlie, E. M., and Baxter, C. F. (1954). Some clinical applications of techniques with tracer doses of ${ }^{59} \mathrm{Fe}$. In Proc. 2nd Radioactive Isotope Confr., 1954, Oxford, vol. 1, pp. 97-106. Butterworth, London.

Leikin, S., and Eng, G. (1963). Erythrokinetic studies of the anemia of lead poisoning. Pediatrics, 31, 996-1002.

McFadzean, A. J. S., and Davis, L. J. (1949). On the nature and significance of stippling in lead poisoning, with reference to the effect of splenectomy. Quart. J. Med., 42 (n.s. 18), 57-72.

Mollison, P. L., and Veall, N. (1955). The use of the isotope ${ }^{51} \mathrm{Cr}$ as a label for red cells. Brit. J. Haemat., 1, 62-74.

Simpson, J. A. (1956). Electrical signs in the diagnosis of carpel tunnel and related syndromes. J. Neurol. Neurosurg. Psychiat., 19, 275-280.

(1962a). The clinical physiology of the lower motor neurone. Dev. Med. Child. Neurol., 4, 55-64.

- (1962b). In Modern Trends in Neurology, 3rd series, ch. 14, edited by $\mathrm{D}$. Williams. Butterworth, London.

- (1962c). Conduction velocity of peripheral nerves in human metabolic disorders. In Progress in Electromyography: Proc. 1st int. Congr. Electromyography, 1961, Paris, pp. 36-43. [Electroenceph. clin. Neurophysiol., suppl. no. 22]. In Progress in Electromyography, edited by P. Pinelli, pp. 36-43. Elsevier, Amsterdam.

- (1964). Biology and disease of the peripheral nerves. Brit. med. J., 2, 709-714.

Wetherley-Mein, G., Hutt, M. S. R., Langmead, W. A., and Hill, M. J. (1956). Radioactive iron studies in routine haematological practice. Brit. med. J.. 1, 1445-1448. 